\title{
SUPERSENSITIZATION TO ALIEN SERUM '.
}

By ALBERT S. GRÜNBAUM, M.D., F.R.C.P.

\author{
(From the Pathological Laboratory, University of Leeds.)
}

THE phenomenon of supersensitization observed on repeated injection of alien sera has lately aroused much experimental and clinical interest. The following cases which led me some three years ago, on clinical grounds to assume the occurrence of this phenomenon, appear worth recording, especially since the reaction happened not with anti-diptheritic or anti-plague but with anti-tuberculous serum.

The reaction occurred in a series of cases treated with the same supply of slightly blood-stained serum and the variation in the results is likely, in my opinion, to be due nearly as much to the presence or stage of the disease as to any idiosyncrasy on the part of the patient.

The histories will show that there was nothing especially and immediately toxic in the serum, but it may be as well to state that the serum was tested after each accident by single injections, on both guinea-pigs and monkeys, without any bad symptom or untoward result.

The serum had been tried in eleven cases, when the occurrence of a death attributable dircetly to the serum made further administration inadvisable.

In no instance did the second injection produce any alarming or uncomfortable effect; the fourth, in one case, was followed by urticaria and other subjective symptoms, on account of which the patient refused further injections; in another case oedema of the tongue and larynx followed two successive injections and the administration was therefore stopped.

Concerning the following five cases more details are given because although the number of injections was large, either no accident happened or it happened suddenly without warning-at any rate the patients had made no previous complaint. The serum was given in series on successive or alternate days for several doses, followed by an

1 Portion of a paper read before the Leeds and West Riding Medico-Chirurgical Society on 11 December, 1906, with references to later literature added subsequently. 
interval of several days before the commencement of the next series. It will be noticed that the bad effects always occurred in the course of a series and not at the commencement.

W. C., male, aet. 40 . This man's temperature was generally under $99^{\circ} \mathrm{F}$. and tubercle bacilli were alleged to have been found on one occasion in the sputum. He had absolutely no symptoms from the serum and left the hospital cured.

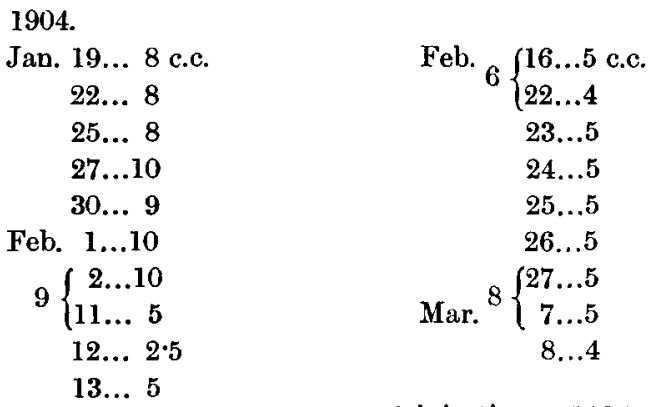

19 injections $=118 \cdot 5$ c.c.

A. H., male, aet. 25. A case of advanced phthisis with a temperature varying at least three degrees in 24 hours and sometimes six degrees. He died on 16 March, 1904. No symptoms attributable to the serum occurred.

1904.

Feb. $1 . . .5$ c.c.

$2 \ldots 5$
$4 \ldots 5$
$5 \ldots 7$
$8 \ldots 8$

Feb. $11 \ldots 6$ c.c.

$12 \ldots 5$

$13 . .5$

$5 . . .7$

$6\left\{\begin{array}{l}16 \ldots 5 \\ 22 \ldots 5\end{array}\right.$

10 injections $=56$ c.c.

The following cases developed serious symptoms.

R. W., male, aet. 31 . A case of phthisis in the third stage, with pyrexia which increased with the injections. He also had an anchylosed hip-joint. Almost immediately after the last injection, he complained of "feeling queer," became cyanosed, vomited, lost consciousness and died within five minutes.

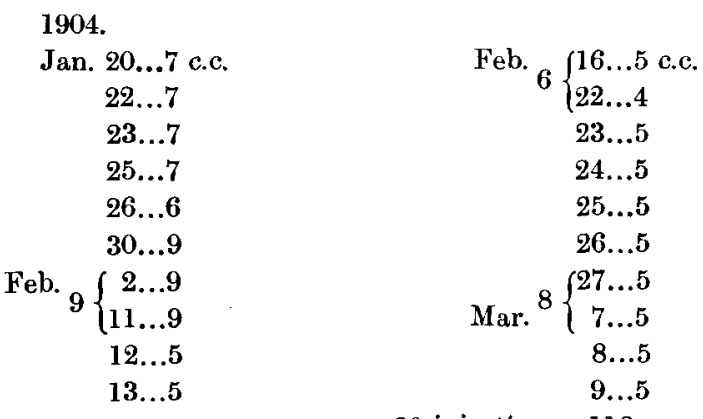

20 injections $=116$ c.c. 
M. S., female, aet. 41. A case of phthisis in late second stage. The temperature reached a higher general level during the serum administration than before and rose yet higher after its cessation. She was discharged, certainly no worse, on 14 March.

About two minutes after injection of serum on Feb. 27 the patient began to feel faint, felt blood rush to head, had sensation of choking and thought she was becoming blind. Objectively, she became suffused a deep bluish red, the eruption appearing on the fore arms and thighs as well as in the face. Subsequently she vomited. Pulse became rapid, 120, and remained so for 24 hours. Pain in front and back of chest for a day.

1904 .

Jan. $25 . . .5$ c.c.

Feb. $16 \ldots 5$ c.c.

$27 \ldots 5$

$5\left\{\begin{array}{l}17 \ldots 5 \\ 22 \ldots 5\end{array}\right.$

Feb. $1 \ldots 7$

$23 . . .4$

$2 \ldots 9$

$24 . .5$

$4 \ldots 9$

$25 . . .5$

$5 . . .9$

$27 \ldots 5$

$8 . .5$

$9 . . .5$

$11 \ldots 5$

$14 \ldots 5$

18 injections $=103$ c.c.

S. M., female, aet. 22. A case of second stage phthisis with pyrexia to $100^{\circ} \mathrm{F}$., rising higher during a few days of the serum administration period with some improvement later.

Only 2 c.c. under the left scapula had been given to this patient when the symptoms arising in the immediately preceding case were observed and the injection consequently stopped. Nevertheless after two minutes patient felt tightness at throat, saw "funny things," was then unable to see and finally lost consciousness. She lay back in bed, flat, waving her arms about with eyes turned upwards and twitching of the face. This condition lasted about a minute. With returning consciousness she complained chiefly of pain in the head, with some tightness and pain on right side of chest, back and front, like the preceding case. She mentioned then that she had had similar pectoral pain after the previous injection. Pulse quick and irregular. Recovery rapid except pulse which remained quick for 24 hours. Discharged improved on 22 March.

1904.

Jan. $27 \ldots 2$ c.c.

$$
30 . . .5
$$

Feb. ${ }_{6}\left\{\begin{array}{l}16 \ldots 5 \text { c.c. } \\ 22 \ldots 1\end{array}\right.$

Feb. $1 \ldots 7$

$23 . . .4$

$3 \ldots 6$

$24 \ldots 5$

$4 \ldots 6$

$25 \ldots .5$

$5 . . .8$

$27 \ldots 2$

$9 . .5$

$11 \ldots 5$

$13 \ldots .5$

$15 \ldots 5$

16 injections $=76$ c.c. 
I record these cases chiefly to add to the necessary array of facts required before we can theorize about the phenomenon. They do not, it seems to me, fit in well with any hypothesis yet put forward, but they tend to diminish the importance of the element of time and to emphasize that of accumulation.

There are two possible factors which have not received much attention in the explanation of the phenomenon: the one is the constitution of the serum, the other the condition of the patient.

So far as anti-diphtheritic serum is concerned, Anderson and Rosenau believe, from their experiments, that antitoxin plays no part. Its effect may have been inappreciable in their experiments although it must be remembered that normal horse serum contains some antitoxin. But they also found that the presence of some toxin appears to increase the supersensitiveness. Consequently while the reaction depends mainly no doubt on a substance peculiar to the alien serum, it may be assisted by the presence of toxin, perhaps neutralized in the serum as injected, but subsequently dissociated in the body. A serum may be antitoxically very potent and yet contain some neutral mixture, and possibly some such dissociation explains in part the relatively slight effect of anti-diphtheritic serum in preventing or mitigating paralysis.

In anti-tuberculous serum it is more than likely that the antitoxin is minimal in amount and that the curative action is largely due to a minute quantity of tuberculin. (The fact that the serum has been found to do good when tuberculin has failed, does not negative this supposition because of the difference in dose.) But the presence of tuberculin may help to induce the phenomenon of "supersensitization" and by its continuous injection produce a deep negative phase of diminished resistance. The alien serum itself acts also like a vaccine so that each succeeding administration, taking place probably during a negative phase, leads up to the final catastrophe.

To a tuberculous patient in whom auto-inoculation is taking place constantly, this additional small dose of tuberculin may make no difference. Nor would it affect a non-tuberculous patient. In this way I explain the indifference of the first two cases above recorded.

Probably the chief factor is personal idiosyncrasy, and this can be determined only by trial. Two rabbits of the same breed may be injected intravenously with 10 c.c. of the same human serum, and one will remain unaffected, while the other will be dead in ten minutes. Again ordinarily harmless substances like eggs, sole, chocolate or strawberries produce toxic effects in some individuals, so that it is 
not remarkable the generally harmless horse serum occasionally produces the same.

Under all circumstances I believe considerable care should be bestowed on cases treated with repeated injections of alien serum, and the injections should be intermitted for a period, as long as compatible with the safety of the patient, as soon as the first sign of "serum disease" appears. In all cases where rectal administration is efficient, it should be preferred to subcutaneous injection.

Had Anderson and Rosenau's experiments with animals been published before the cases related above were treated, some of the accidents might have been avoided.

\section{REFERENCE.}

Currie, J. R. (II. 1907). On the supersensitation of persons suffering from diphtheria by repeated injections of horse serum. Journ. of Hygiene, vol. vir. p. 35. (References to all the important literature are given.) 